\title{
FACULTY ENGAGEMENT \\ IN PROGRAM-LEVEL \\ OUTCOMES ASSESSMENT
}

\author{
A LEARNING PROCESS
}

\section{Elizabeth L. Evans}

Concordia University Wisconsin

Faculty are often not seen as engaged in the work of program-level student learning outcomes assessment. This study investigates the experiences of faculty who self-identified as engaged, a term used to describe attitudes of excitement as well as participatory behaviors. To encourage faculty engagement and recognize the learning process that engagement embodies, institutions can provide faculty development or role catalysts, an environment that values assessment work, support for learning, and opportunities for faculty members to make contributions using what they have learned.

0

Public pressure to measure quality in higher education has emerged in the past two decades as higher education has come to be perceived as an economic necessity for students and the nation rather than as an "optional indulgence" for some students (Suskie, 2006, p. 15). The slipping competitive position of the United States compared to other countries has led to broader bipartisan agreement on the need for increased educational attainment, and higher education institutions are now being asked to respond with transparency in sharing results of student 
performance on student learning outcomes (Ewell, 2009). One example, Measuring Up 2000 (National Center for Public Policy and Higher Education, 2009), created a report card for each state on higher education benchmarks of student success.

In 2006, the Spellings Commission (U.S. Department of Education, 2006) called on higher education institutions to demonstrate accountability through improvement in access, affordability, and assessment of learning outcomes. Outcomes assessment at the program level is undertaken for two perceived purposes: accountability and improvement (Ewell, 1987). In a survey of provosts and chief academic officers, Kuh and Ikenberry (2009) found that on a scale of $1=$ not at all used and 4 = used very much, assessment data were most frequently used for institutional (3.27) and program (3.24) accreditation. By contrast, improving instructional performance and improving the general education curriculum were each rated at approximately 2.5 out of 4.0 in this survey. Faculty development offerings related to outcomes assessment showed a high level of discrepancy between importance and availability in a survey of faculty developers on top teaching and learning issues by Sorcinelli, Austin, Eddy, and Beach (2006). Respondents agreed that delivery of outcomes assessment programs was and would continue to be important, but one respondent noted that "assessment is increasingly being used to measure institutional accountability ... rather than to assist faculty in clarifying teaching goals and understanding student needs" (p. 82). Accordingly, faculty developers who integrate knowledge about effective outcomes assessment practice with teaching and learning work already recognized as crucial to student learning (for example, course redesign or general education development) may be more successful in assisting in the development of faculty engagement in outcomes assessment.

Most institutions lag in fully implementing assessment processes and using outcomes data to improve student learning. Blaich and Wise (2011) found that even with guidance and support, only about 25 percent of the 2006 cohort of institutions participating in the Wabash National Study of Liberal Arts Education developed active responses to outcomes assessment data after four years. Blacklaw (2008) found only moderate success in demonstrating that outcomes assessment data were being used to improve classroom instruction in eight universities in one system. If these indicators are the norm, institutions and faculty need to improve their assessment processes to use assessment data for improving student learning in order to meet the continuing escalation of accountability pressure. 
Higher education institutions are looking for opportunities to engage faculty in the work of outcomes assessment at the program and general education levels. Knowledge of assessment practices and pitfalls is necessary, but active interest and involvement by faculty who are responsible for the process of improving teaching and learning in their departments or programs are key to both institutional effectiveness and continued accreditation. Kuh and Ikenberry (2009) found that 66 percent of institutional leaders who responded felt that increased faculty engagement would be helpful in more effectively assessing and using student learning outcomes on their campuses.

Unfortunately, the institutional effectiveness literature suggests that faculty are resistant to this type of work, which they often see as a requirement of external accountability and an additional burden to their roles of teaching, research, and service. Faculty satisfaction with institutional approaches to measuring institutional effectiveness (Grunwald \& Peterson, 2003), involvement (Jacobson, 2001), or participation has been examined, but no definition of faculty engagement appears in the practitioner or research literature on outcomes assessment. Little is therefore known about faculty who are engaged in outcomes assessment or what is meant by the term engagement, though it is used repeatedly in the practitioner literature on outcomes assessment (see Banta, 2004). Two studies have included interviews with faculty about positive experiences with assessment (Johnson, 2007; Verberkmoes, 2006) and found the work benefited their teaching or administrative duties within their departments and colleges. Promisingly, Ewell (2009) found that "a sizeable minority of faculty have wholeheartedly embraced assessment as useful in improving undergraduate instructiona constituency of adherents that did not exist a quarter century ago" (p. 6).

\section{A Qualitative Study of Engaged Faculty}

I examined the experiences of higher education full-time faculty members at teaching-intensive institutions who described themselves as already engaged in program-level outcomes assessment to learn how they described their engagement and what factors they associated with it. By focusing research on this emerging group of adherents, I hope to launch further research to refine the preliminary definition of engagement developed in this study; give voice to their experiences; and identify patterns of attitudes, behaviors, or contextual factors that assist in the development of engagement in outcomes assessment work. Research on these faculty experiences will provide faculty leaders, administrators, and assessment leaders with more information and tools to address the 
exigencies of today's higher education environment regarding the engagement of faculty in outcomes assessment at their campuses.

\section{Study Participants and Methods}

To determine whether there was a common experience of engagement among participants and to capture the phenomenological essence of their experience, this study used purposeful sampling to identify individuals who could describe experiences of engagement (Evans, 2010). Eligible participants were full-time faculty members at nonprofit private or public baccalaureate or master's institutions regionally accredited by the Higher Learning Commission, either teaching or working in an academic administrative role such as assessment director, who described themselves as taking initiative in and feeling a commitment to the work of program-level student learning outcomes. These parameters were chosen to create some level of similar background among participants in assessment expectations and the experience of a teaching-intensive institution. Potential participants were identified through my networks, institutional Web sites, the POD listserv, conference attendee lists, or referral. A recruitment letter was sent to individuals identified through these methods to determine if they fit study parameters; referrals were also sought through the letter.

Ultimately I identified ten individuals available for interviews in fall 2009. I conducted in-person interviews with six of them and telephone interviews with the others. Five of the participants were men and five were women; eight had Ph.D.s, one had an Ed.D., and one had an M.A. as the highest earned degree. Phenomenological interviews were conducted inquiring about the history and context of experiences with engagement and the meaning they ascribed to those experiences. All participants were or had been involved in some institutional responsibility for program-level assessment.

\section{Findings}

After analysis of the data through a phenomenological process, described by Giorgi (1997), involving bracketing, description, and the search for the essence of experiences, I discerned themes related to a common experience of engagement among participants that included both affective and behavioral elements. Participants were either role oriented (those whose catalyst related to assessment-related roles) or teaching and learning oriented (those whose catalyst arose out of faculty development experiences or conversations with colleagues about teaching and learning). 
Participants collectively defined engagement as a set of both positive attitudes and dedicated behaviors involved in using assessment as a process to improve student learning. All embraced improvement of student learning as the primary purpose of assessment (Ewell, 1987, 2009), seeing learning and student performance as having greater value than institutional accountability. Participants overcame the notion that assessment was being done primarily for external purposes and desired to participate in assessment activities as a benefit to student learning. At the same time, they recognized the need to conduct outcomes assessment as a requirement from accrediting bodies. Participants described their engagement in terms connoting energy and enthusiasm for the work, including eager, enthusiastic, and excited. Engagement was found to include such affective elements, distinguishing it from mere participation. Engaged faculty described both positive attitudes and dedicated behaviors, were excited about outcomes assessment as a means to improve student learning, and sought and found the opportunities to have conversations with colleagues about student learning meaningful. Engaged faculty members were also interested in proactively improving the processes they used and believed assessment was an opportunity to think systematically about institutional improvement. Attitudes and behaviors of engagement as described by participants and identified as themes by the researcher are displayed in Table 3.1 .

\section{Table 3.I. Faculty Engagement Attitudes and Behaviors.}

\section{Attitudes}

Believing that outcomes assessment is a process for improving student learning

Being excited about assessment as an opportunity for improvement

Caring about the process and improving it

Viewing assessment as a way to work collaboratively with colleagues

Seeing assessment as a way to think systematically about institutional improvement
Behaviors

Spending time and energy on assessment work

Integrating classroom assessment with program-level assessment

Contributing to the successful work of assessment on campus, including seeking ways to improve it

Participating in meaningful conversations about using assessment data to improve teaching, learning, and the institution at both departmental and institutional levels 
One participant, for example, suggested that although she had always been interested in student learning as a faculty member, her own learning about and engagement with assessment allowed her to become more intentional about student learning in individual class sessions. Another's view of engagement focused on her habit of thinking about student outcomes and student performance at the department level that developed in her engagement process. She thinks about student assessment and student outcomes first, and since becoming engaged with assessment she makes decisions about teaching methods based on the outcomes she wants students to achieve at the end of the course. Previously she had felt driven more by the need to cover a certain amount of content than by the ability to affect student performance.

\section{Two Paths of Engagement}

Two groups emerged among study participants. One group was teaching and learning oriented, finding interest in outcomes assessment initially within a context of faculty development experiences or through dialogue and conversation with colleagues about student learning. The other, a role-oriented group, began learning about assessment because of their responsibility for outcomes assessment within their department or institution. Identification of these divergent paths is valuable in informing leaders, administrators, and faculty developers on how to locate faculty who might be moving toward engagement and encourage development of positive attitudes toward engagement through the three phases of engagement: catalyst, learning, and contribution (Figure 3.1).

\section{Phase 1: Encountering a Catalyst}

Role-oriented faculty experienced the catalyst that began their engagement when they accepted a departmental or institutional leadership role

Figure 3.I The Three Phases of Engagement: Catalyst, Learning, and Contribution.

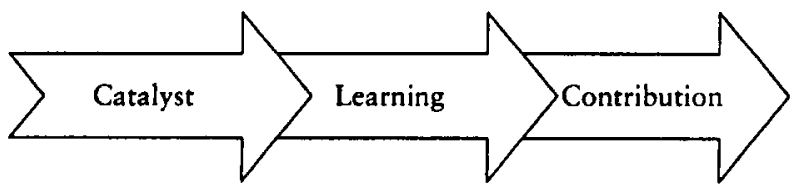


in assessment activities. When study participants began this work, they felt compelled to learn about assessment at the program level and effective assessment practice. In contrast, the catalysts for teaching-andlearning-oriented faculty were moments of sudden awareness or new learning paradigms they discovered while working to improve their teaching. They began the process of engagement in outcomes assessment during faculty development opportunities related to teaching and learning or during conversations with departmental colleagues about what their students were learning.

\section{Phase 2: Learning and Discovery}

Most teaching-and-learning-oriented faculty began their path to engagement through faculty development programs providing experiences in which they developed a greater understanding of their own teaching, particularly learner-centered teaching. As they began thinking about pedagogy and student learning, they realized that program-level assessment beyond the classroom was an important part of their responsibility for improving student learning. This group was thus already engaged in outcomes assessment when they accepted institutional assessment roles.

Learning was more focused and time delimited in the role-oriented group, whose members embraced a time of learning and discovery about outcomes assessment after they accepted an institutional role of responsibility for assessment. Faculty in this group took on roles such as faculty coach for a grant on outcomes assessment and interactive learning, department chair, departmental or divisional assessment representative charged with carrying out program-level assessment and serving on a faculty assessment committee, assessment committee member or chair of such a committee, or assessment director charged with oversight of all academic assessment within a school or across the institution. This group focused on self-directed learning such as reading books, attending conferences, seeking out peers and mentors, and working with consultants. The period of learning was more distinct for the role-oriented faculty: they often sought out learning within the first six months of accepting an assessment role. Phase 2 for teaching-and-learning-oriented faculty overlapped with phase 3 . Both groups continued to learn and develop as they moved into the next phase.

Recognizing a need for learning, one participant immersed herself in books and conferences and learned through colleagues in other schools 
and by completing her own department's assessment. She explained that learning was the antidote to the initial confusion she felt on accepting the position of assessment coordinator. Another highlighted the support he received from senior administrators in providing resources for learning, including time and financial resources. A third stepped up to serve as the director of assessment because no one else seemed to be willing. He explained that his prior service on the committee had begun his education in assessment, but once he began attending conferences, reading books, and undertaking the work of assessment director, he "really started to learn."

All participants described their engagement as the interplay between self-directed learning and experiential learning throughout the phases. Both of these learning processes were well represented in the initial catalytic phase; self-directed learning was more prominent in the second phase, and experiential learning was more prominent in the third phase.

\section{Phase 3: Sustained Contribution}

Whereas the paths of teaching-and-learning-oriented faculty and roleoriented faculty diverged in phases 1 and 2, both groups worked toward the improvement of student learning through sustained contributions to their institutions using their knowledge and engagement. Activities included leadership on committees, serving as a first-year-experience director, moving into administrative roles, and working to improve general education. Participants continued learning as in earlier phases, but experiential learning was particularly evident in this phase as participants used what they had learned about effective assessment process as they participated in and led academic work in which knowledge of outcomes assessment was beneficial.

Participants valued assessment work with colleagues as an opportunity to create meaningful conversations about teaching and learning. For example, one participant saw that working on assessment "in a smart efficient way would facilitate conversations about teaching and learning that would form the collegial bonds I like, the collegium, and the collaboration." Another felt that having meaningful conversations at both the faculty and the administrative levels was an important part of being engaged in assessment. Another participant indicated that while she could think by herself about her own courses, she needed to be in communication and conversation with her departmental colleagues on how her courses fit within the program. 


\section{Encouraging and Hindering Factors}

While much of the experience of engagement was an internal one, factors within the institutional context were perceived as either encouraging or hindering participants' engagement. In the first phase, opportunities for catalytic experiences required institutional investment in faculty development and an infrastructure supporting assessment processes within departments and general education. One participant's experience at a faculty development seminar was possible because she had received a grant to participate. Progress through the second phase depended on the presence of opportunities for reflection to occur, included being given sufficient time and financial support for learning (purchase of books, attendance at conferences, the opportunities to interact with peers outside the institution). While faculty members at her own campus were not yet finding value in assessment work, another participant found support and encouragement from peers outside her institution during work on a multicampus grant project. Another's phases of engagement were supported by the positive energy from colleagues; "one of the smarter things" he ever did was to look up and network with peers at sister institutions. Encouraging factors in the phases of engagement included support in the form of mentoring relationships, a cadre of interested faculty peers, positive attitudes toward assessment as an improvement process in the organization, and senior institutional leaders who invested resources and financing for learning opportunities and publicly acknowledged the value of the work done by those engaged in outcomes assessment work.

Several participants recognized lack of financial support or other demonstrations of support for assessment by senior institutional leaders as a challenge, and resistance from faculty peers as a barrier, to effective collaborative work. Prior to her engagement, one participant felt that no one in the academic office was paying attention to her assessment reports, but once meaningful feedback was offered by administrators and expectations made of her department to be accountable for their assessment work, she became more interested. Another participant sighed during the interview when talking about lack of respect for assessment demonstrated by faculty and administrators at his prior employer. He felt that his efforts to get faculty engaged at that institution failed because of a culture that placed a lower value on assessment than other faculty work. Resistance by faculty peers to assessment was a formidable challenge for other participants, who stated that interest seemed to wax and wane with the accreditation cycle instead of being recognized as an important recurring process. Thus, institutional culture affected engagement through the 
context surrounding participants and the level of support they received from peers and administrators.

\section{Implications}

This study presents attitudes and behaviors that engaged a small group of faculty members in outcomes assessment. While qualitative research is not necessarily generalizable beyond localized contexts and cases (Patton, 2002), these faculty stories illustrate key factors in engagement and indicate that viewing assessment work as a systematic opportunity to improve student learning was the strongest motivator for becoming engaged. This finding should inform faculty and assessment leaders, senior administrators, and faculty developers in seeking to create an environment in which faculty members might become engaged. With faculty who are moving toward engagement in outcomes assessment appearing as role oriented or teaching and learning oriented, a successful approach to engagement involves deploying resources for both faculty development (to draw out potential teaching-and-learning-oriented faculty) and the creation of structures of faculty roles of responsibility within departments supported by resources for learning (as a means to develop role-oriented faculty on the path toward engagement). The study further recommends the use of responsibility, resources, and rewards (Palomba \& Banta, 1999) within an intentional framework of learning opportunities for faculty.

Perhaps the easier approach to fostering engagement is to assign roles of responsibility for coordinating assessment activities to one person in each department. Since the doorway to periods of intense learning for many of the participants came when they were given such responsibilities, identifying an assessment coordinator to take on responsibility in each department would seem to be one way to begin the process of increasing engagement on campus. Faculty development and learning resources should follow.

\section{Internal Motivation and Culture}

Faculty who saw improvement as the most important purpose of outcomes assessment found personal meaning in their contributions to improving their students' learning through outcomes assessment work. A sense of personal ownership, or engagement, included the affective elements of attitude, energy, and enthusiasm, which are triggered by interior individual experiences. Engaged faculty members individually embraced the improvement purpose of assessment and desire to use assessment to 
improve student learning despite elements opposing this within the culture of their organizations. Engagement cannot be mandated, but it can be fostered by a culture that shows concern for student learning and attitudes that value outcomes assessment work, supported by investing in those outcomes.

Participants in this study described organizational cultures that contributed to their learning or hindered their engagement. Faculty colleagues and administrative leaders played important roles in creating an environment fostering collaboration and dialogue about student learning. Individuals in leadership positions can emphasize the view of assessment on campus as an improvement process rather than focusing on accountability as the primary driver of the work. A faculty and organizational culture that values learning about assessment and leadership in improvement of student learning could give faculty the opportunity to discover outcomes assessment as an improvement process and provide support to transform an interest into engagement.

\section{A Teaching and Learning Process}

The development of positive attitudes toward assessment in faculty can be seen as a teaching and learning process to be planned and implemented by campus leaders and faculty developers. Leaders need to demonstrate their own interest and engagement in the activities of assessment on campus. Outcomes assessment is asking a series of important questions about teaching and learning (Hutchings \& Marchese, 1990). Accordingly, institutional leaders can ask: what do we want our faculty to know, do, and value so they can embrace outcomes assessment as a meaningful way to improve their teaching and their students' learning? When leaders see engagement as a faculty learning process, they can identify the tools available to support adult learning in the form and practices of adult education and development. Faculty developers are knowledgeable in these areas and in helping to create effective learning environments. When leaders see engagement as a faculty learning process, they will want to deploy resources to support that learning-an experiential, cyclical learning process that requires practice, reflection, and process improvement.

\section{Responsibility, Resources, and Rewards}

Palomba and Banta (1999) suggested that the three Rs of responsibility, resources, and rewards are necessary to overcome faculty resistance to work on outcomes assessment. The rewards that faculty receive from the 
institution affect their perception of the value of assessment work. Hutchings (2010) suggested that an obstacle to faculty involvement in outcomes assessment work is that the work does not fit typical institutional reward systems and is undervalued.

Outcomes assessment work has often been seen as service within the faculty work of teaching, research, and service (Johnson, 2007; Schilling \& Schilling, 1998). Brocker (2007) found that this categorization did not promote participation. Instead, if faculty could perceive assessment as related to their teaching or their scholarship, their resistance might drop. Angelo (2002) suggested reframing assessment as scholarship akin to the scholarship of teaching and learning (SoTL), so that faculty might publish and present their findings to peers. Ewell (2002) described the emergence of a scholarship of assessment as one of the precursors to the further development of assessment as faculty work which is valued.

Organizational reward systems that do not embrace outcomes assessment as an important part of teaching or scholarship are unlikely to foster faculty engagement in that area. Scholarship on outcomes assessment has the potential to improve student learning and should be considered in promotion and tenure decisions, particularly in teaching-intensive institutions. Among the resources that can be brought to support assessment are assigning responsibility for implementation, providing reading materials, and bringing consultants to campus for presentations. Opportunities for reflection on learning and networking with other faculty interested in assessment encourage engagement. Resources can be allocated to reward faculty to develop assessment projects using stipends, release time from teaching, or travel fund grants (Palomba \& Banta, 1999). Attending conferences is valuable, as nine of the ten participants in this study reported.

\section{What Faculty Developers Can Do}

The faculty development literature has not embraced a thoughtful and integrative approach to improving faculty engagement in outcomes assessment as a faculty development intervention at the group level of organization development. Hutchings (2010) opined that outcomes assessment inquiry should grow out of faculty questions about student learning and the regular ongoing work of teaching. To this end, faculty developers might also seek to develop collaborative learning opportunities such as communities of inquiry within programs, those who teach general education courses, or across campus. The purpose of collaborative inquiry is to explore individual and group responses to a dilemma they face (Kasl \& Yorks, 2002). In such learning experiences, questions 
are asked, answers are sought, and reflection and dialogue on the questions and answers foster learning. Faculty engaged in collaborative inquiry strategies about teaching and learning are more likely to find assessment conversations to be worth their time and investment.

\section{Scholarship of Teaching and Learning}

Hutchings, Huber, and Ciccione (2011) argued that there has been a wide chasm between the grassroots, classroom-focused, data-driven practice of the SoTL and the institution-focused need for effective program-level outcomes assessment practice. Yet they saw possibilities and bridges across this rift being formed. Centers can integrate teaching and learning with outcomes assessment in a number of effective ways. Learning through reflective practice can be brought to a scholarly level by encouraging faculty to share experiences through SoTL, other action research projects, the practice of learning communities, or collaborative inquiry (Bray, 2002). SoTL and action research projects can be disseminated in publications or presentations. Faculty developers working with individual faculty members on their course-level assessment could expand this work to the department level. They can include reference to program-level learning outcomes when they teach course redesign workshops, highlighting for faculty the connection between individual course and programmatic outcomes.

\section{Systematic and Sustained}

When faculty developers frame course, program, general education, and institutional-level learning outcomes as interconnected, faculty will be more prepared to work toward outcomes assessment processes at the program and general education levels. Faculty developers can also work directly with assessment leaders to provide learning support for faculty about the processes of outcomes assessment at the program level. Huba and Freed (2000) argued that faculty development that supports assessment must be systematic and sustained. They suggested that faculty need to understand multiple assessment elements such as developing measurable outcomes, designing rubrics to evaluate student work, conducting data analysis, and documenting the work.

While developing programs that develop faculty who become and remain engaged in outcomes assessment is complex and unfolds over time, the potential rewards in student improvement, faculty satisfaction, and institutional accountability seem well worth the efforts. 


\section{REFERENCES}

Angelo, T. A. (2002). Engaging and supporting faculty in the scholarship of assessment: Guidelines from research and best practice. In T. W. Banta (Ed.), Building a scholarship of assessment (pp. 185-200). San Francisco, $\mathrm{CA}$ : Jossey-Bass.

Banta, T. W. (2004). That second look at student work: A strategy for engaging faculty in outcomes assessment. In T. W. Banta (Ed.), Hallmarks of effective outcomes assessment (pp. 37-42). San Francisco, CA: Jossey-Bass.

Blacklaw, S. T. (2008). Affecting change in the State University of New York: Linking the locus of commitment to effective assessment. Dissertation Abstracts International, 69(08). (UMI No. 3060501)

Blaich, C., and Wise, K. (2011, January). From yathering to using assessment results: Lessons from the Wabash National Study (NILOA Occasional Paper No. 8). Champaign, IL: National Institute for Learning Outcomes Assessment. Retrieved from http://www.learningoutcomeassessment.org/ documents/Wabash_001.pdf

Bray, J. N. (2002). Uniting teacher learning: Collaborative inquiry for professional development. In L. Yorks \& E. Kasl (Eds.), New directions for adult and continuing education: No. 94. Collaborative inquiry as a strategy for adult learning (pp. 83-91). San Francisco, CA: Jossey-Bass.

Brocker, J. (2007). Involving faculty in assessment activities associated with AACSB assurance of learning standards. Dissertation Abstracts International, 68(3). (UMI No. 3253731)

Evans, E. L. (2010). Experiences of higher education faculty engaged in undergraduate student learning outcomes assessment. Dissertation Abstracts International, 72(03). (UMI No. 3441983)

Ewell, P. T. (1987). Assessment, accountability, and improvement: Managing the contradiction. American Association for Higher Education Assessment Forum. ED 287330.

Ewell, P. T. (2002). An emerging scholarship: A brief history of assessment. In T. W. Banta (Ed.), Building a scholarship of assessment (pp. 3-25). San Francisco, CA: Jossey-Bass.

Ewell, P. T. (2009, November). Assessment, accountability, and improvement: Revisiting the tension (Occasional Paper No. 1). Champaign, IL: National Institute for Learning Outcomes Assessment Retrieved from http://www learningoutcomeassessment.org/occasionalpaperone.htm

Giorgi, A. (1997). The theory, practice, and evaluation of the phenomenological method as a qualitative research procedure. Journal of Phenomenological Psychology, 28(2), 235-260. 
Grunwald, H., \& Peterson, N. W. (2003). Factors that promote faculty involvement in and satisfaction with institutional and classroom assessment. Research in Higher Education, 44, 173-204.

Huba, M. E., \& Freed, J. E. (2000). Learner-centered assessment on college campuses: Shifting the focus from teaching to learning. Needham Heights, MA: Allyn \& Bacon.

Hutchings, P. (2010, April). Opening doors to faculty involvement in assessment (NILOA Occasional Paper No. 4). Champaign, IL: National Institute for Learning Outcomes Assessment. Retrieved from http://www.learningoutcomeassessment.org/occasionalpaperfour.htm

Hutchings, P., Huber, M. T., \& Ciccione, A. (2011). The scholarship of teaching and learning reconsidered: Institutional integration and impact. San Francisco, CA: Jossey-Bass.

Hutchings, P., \& Marchese, T. (1990). Watching assessment: Questions, stories, prospects. Change, 22(5), 12-38.

Jacobson, A. B. (2001). Involvement of faculty in higher education assessment practices. Dissertation Abstracts International, A62(05). (UMI No. 3015411)

Johnson, L. G. (2007). Faculty involvement in scholarly assessment: A phenomenological study. Dissertation Abstracts International, 69(03). (UMI No. 3305926)

Kasl, E., \& Yorks, L. (2002). Collaborative inquiry for adult learning. In L. Yorks \& E. Kasl (Eds.), New directions for adult and continuing education: No. 94. Collaborative inquiry as a strategy for adult learning (pp. 3-12). San Francisco: Jossey-Bass.

Kuh, G. E., \& Ikenberry, S. (2009). More than you think, less than we need: Learning outcomes assessment in American higher education. National Institute for Learning Outcomes Assessment. Retrieved from http://www .learningoutcomeassessment.org/NILOAsurveyresults09.htm

National Center for Public Policy and Higher Education. (2009). Measuring up 2006. Retrieved from http://measuringup.highereducation.org/about/

Palomba, C. A., \& Banta, T. W. (1999). Assessment essentials: Planning, implementing, and improving assessment in bigher education. San Francisco, CA: Jossey-Bass.

Patton, M. Q. (2002). Qualitative research and evaluation methods (3rd ed.). Thousand Oaks, CA: Sage.

Schilling, K. M., \& Schilling, K. L. (1998). Proclaiming and sustaining excellence: Assessment as a faculty role. ASHE-ERIC Higher Education Report 26(3). Washington, DC: George Washington University, Graduate School of Education and Human Development. 
Sorcinelli, M. D., Austin, A. E., Eddy, P. L., \& Beach, A. L. (2006). Creating the future of faculty development: Learning from the past, understanding the present. San Francisco, CA: Jossey-Bass/Anker.

Suskie, L. (2006). Accountability and quality improvement. In P. Hernon, R. E. Dugan, \& C. Schwartz, (Eds.), Revisiting outcomes assessment in higher education (pp. 13-38). Westport, CT: Libraries Unlimited.

U.S. Department of Education. Secretary of Education's Commission on the Future of Higher Education. (2006). A test of leadership: Charting the future of U.S. higher education. Retrieved from http://www.ed.gov/ about/bdscomm/list/hiedfuture/reports/final-report.pdf

Verberkmoes, J. F. (2006). Student outcomes assessment: A study of the organizational factors that foster or inhibit progress in establishing a culture of assessment within graduate theological schools. Dissertation Abstracts International, 67(05). (UMI No. 3216183) 